\title{
New dedicated blunt straight needles and sutures for uterine compression sutures: a retrospective study and literature review
}

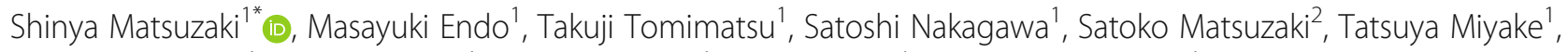
Tsuyoshi Takiuchi', Aiko Kakigano', Kazuya Mimura', Yutaka Ueda' and Tadashi Kimura'

\begin{abstract}
Background: We developed a dedicated blunt straight needle with No. 2 polydioxanone sutures (2-Monodiox ${ }^{\circledast}$ for uterine compression sutures (UCSs) and aimed to assess the outcomes and complication rates of UCSs for postpartum hemorrhage by comparing with commercially available needle and suture types.

Methods: A retrospective analysis was performed between January 2010 and February 2018. During the study period, two types of commercially available sutures and 2-Monodiox ${ }^{\oplus}$ were used. PubMed, MEDLINE, and Scopus databases were searched for English articles published between January 1997 and May 2017 using search terms related to the suture and needle types for UCSs to discuss the dedicated needles and sutures for UCS.

Results: The analysis included 47 cases of UCSs for the uterine body with three suture types (No. 0 polydioxanone, 7 cases; No. 1 poliglecaprone 25, 21 cases; and No. 2 polydioxanone, 19 cases). B-Lynch suture using No. 0 sutures was associated with a significantly lower uterine preservation rate than those with Nos. 1 and 2 sutures (42.9\% vs. 95.2 and $89.5 \%$, respectively; $p<0.01$ ). A modified Hayman suture technique was performed using 2-Monodiox ${ }^{\oplus}$ sutures, which achieved a similar uterine preservation rate compared with B-Lynch suture using No. 1 poliglecaprone 25 sutures. No patients developed severe complications. The literature review showed that no dedicated sutures have developed for UCSs. Three dedicated needles for UCSs have been developed, and 2-Monodiox ${ }^{\circledast}$ is the first dedicated blunt straight needle for UCSS.

Conclusion: Our data showed that No. 0 sutures should not be used for B-Lynch suture. The uterine preservation rate is similar for 2-Monodiox ${ }^{\oplus}$ with modified Hayman suture and No. 1 poliglecaprone 25 sutures with B-Lynch suture, without the occurrence of severe complications.
\end{abstract}

Keywords: Uterine compression suture, Needle, Blunt, B-Lynch, Hayman suture

\section{Key message}

Our dedicated blunt straight needle with No. 2 polydioxanone sutures (2-Monodiox ${ }^{\circ}$ ) could perform modified Hayman suture with similar uterine preservation rate performed with B-Lynch technique with No. 1 sutures.

\section{Background}

Postpartum hemorrhage (PPH) is an obstetrical emergency occurring in $4-6 \%$ of live births $[1,2]$. Uterine

\footnotetext{
* Correspondence: zacky@gyne.med.osaka-u.ac.jp

1 Department of Obstetrics and Gynecology, Osaka University Graduate

School of Medicine, 2-2 Yamadaoka, Suita, Osaka 565-0871, Japan

Full list of author information is available at the end of the article
}

compression sutures (UCSs) have been used for the management of $\mathrm{PPH}$ and for avoiding the need for hysterectomy since the introduction of the B-Lynch suture technique in 1997 [3-6]. Various UCSs technique, such as B-Lynch suture, Hayman suture, Cho suture, Pereira suture, and Matsubara Yano suture, have been developed and reported high uterine preservation rate [4, 7-9]. These studies have shown that UCSs are very important techniques for PPH. Also, various studies have focused on the type of UCSs technique.

On the other hand, studies about dedicated needles and sutures for UCSs are limited, and the differences in the efficacies of a needle and sutures have not been

(C) The Author(s). 2019 Open Access This article is distributed under the terms of the Creative Commons Attribution 4.0 International License (http://creativecommons.org/licenses/by/4.0/), which permits unrestricted use, distribution, and 
compared. Several studies did not even mention about the needles and sutures [10-12] and Polyglactin 910 and Catgut sutures appears to be used in many studies [13-15]. However, detailed information is difficult to obtain because the literature review about sutures and needles for UCSs have not been reported. Therefore, our study focused on the efficacy of needles and sutures for UCSs.

First, we show detailed information about our dedicated blunt straight needle with No. 2 polydioxanone sutures (2-Monodiox ${ }^{\circ}$, Alfresa Pharma Co., Osaka, Japan) specially made for UCSs. Our study is the first report of 2-Monodiox ${ }^{\circ}$ for UCS. Next, the efficacy of different needles and sutures for UCSs used at our institution were compared.

Here, the analysis was performed to examine the data of UCSs in our institution and to determine the efficacy of different needle and suture types for UCSs, including 2-Monodiox ${ }^{\oplus}$.

\section{Methods}

\section{Data retrieval}

A retrospective analysis of the clinical outcome of patients with PPH treated using UCSs for the uterine body due to atonic bleeding was performed to assess the efficacy of a dedicated needle and to compare the uterine preservation rate for each suture type. Data were reviewed from the medical records of women who underwent UCSs during cesarean delivery due to atonic bleeding at the Osaka University Hospital, Japan, between January 1, 2010, and February 28, 2018. Women with PPH provided informed consent before undergoing surgery with UCSs. The indications for the use of UCSs have been previously described [5]. In principle, UCSs are only used in cesarean deliveries and when the clinician considers that PPH is persistent, with an estimated blood loss of $\geq 1500 \mathrm{~mL}$. Therefore, women undergoing UCSs were included in our analysis only if the intraoperative blood loss was $>1500 \mathrm{~mL}$. To control PPH due to atonic bleeding, either B-Lynch sutures, as described by B-Lynch et al. with or without some modification [4], or modified Hayman sutures were used as UCSs [7]. A 4-8 week follow up examination was conducted, and the patients were educated to come to our institution to undergo further follow ups if the patients experienced abnormal symptoms, such as abdominal pain, menstrual disorder, and dysmenorrhea.

\section{Dedicated needle and suture for UCS}

To the best of our knowledge, no dedicated straight blunt needle has been developed for UCSs. In Japan, a dedicated $80-\mathrm{mm}$ straight blunt needle was developed by Alfresa Pharma Corporation and Osaka university for use with a 90-cm No. 2 polydioxanone suture (2-Monodiox $\left.^{\circ}\right)$. As shown in Fig. 1, the needle tip is extremely blunt and cannot tear the surgeon's glove but can easily
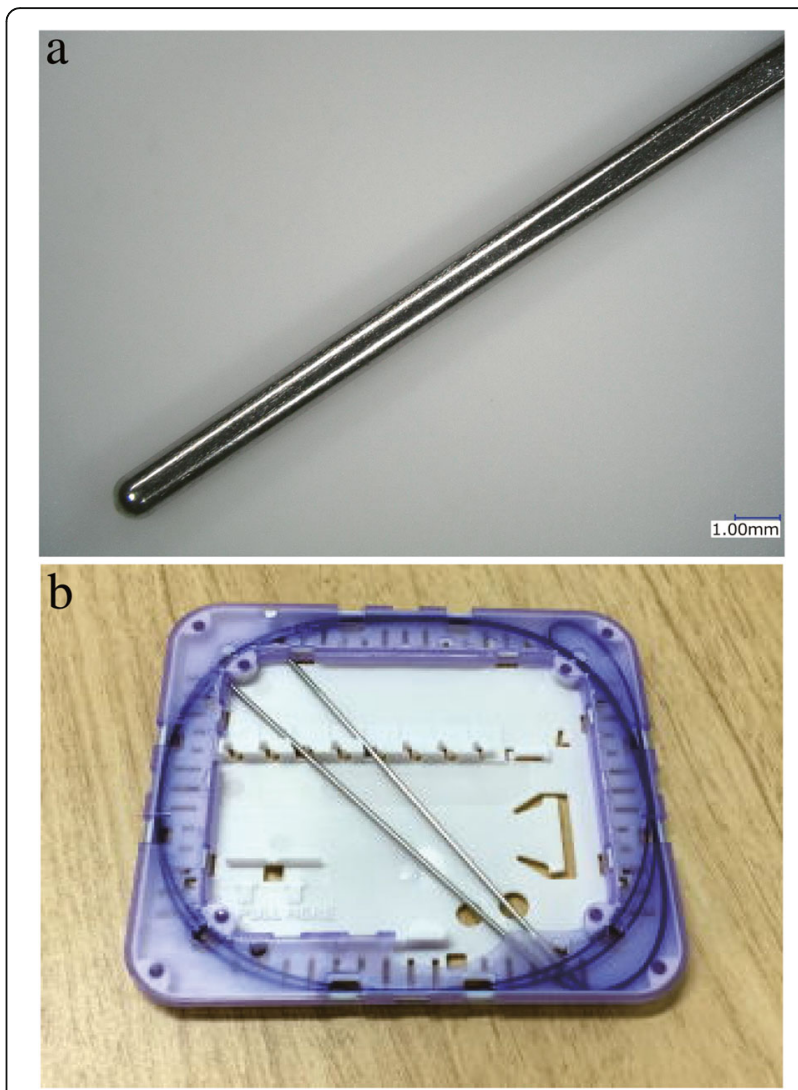

Fig. 1 A dedicated blunt straight needle and sutures for UCSs were developed. The lengths of the needle and suture are 80 and $90 \mathrm{~cm}$, respectively. (a) The needle was made as blunt as possible to avoid the tearing of the surgeon's glove, bladder, bowel, and rectum, but to easily penetrate the uterine wall in the anterior to posterior direction. (b) The difference in the diameter between the needle and suture was kept minimum, with a final diameter of $0.3 \mathrm{~mm}$ to prevent bleeding from the sutured site

penetrate the uterine wall in the anterior to posterior direction (Additional file 1).

\section{Suture types}

We changed the needles and sutures for UCSs thrice to enhance the effectiveness; therefore, three groups based on UCS were formed for analysis. The indications for the use of UCSs in our institution have been mentioned previously [3].

Between January 1, 2010, and August 30, 2013, the B-Lynch suture technique was mainly performed with 48-mm 1/2 circle taper point with 0-PDS ${ }^{\circ}$ (Z990G; Ethicon Endo-Surgery, Inc., Cincinnati, OH, USA), because the choice of the needle and suture for UCS was limited in our institution (during this period, some surgical records did not describe the suture or needle type used; group A). After September 2013, the B-Lynch technique was performed with a 70-mm 1/2 circle blunt needle and 1-Monocryl ${ }^{\circ}$ sutures (W3709; Ethicon Endo-Surgery, Inc.), because this 
needle was not marketed in Japan until June 2013 (group B). In Japan, a dedicated needle (2-Monodiox ${ }^{\circ}$ ) and suture were developed by Alfresa Pharma Corporation (Osaka, Japan) and Osaka University to place UCSs more easily and efficiently. Subsequently, the 2-Monodiox suture was used to perform the modified Hayman suture technique (group C) from August, 2016.

\section{Factors}

To identify the dedicated needles and sutures for UCSs we performed a literature review. We conducted an electronic search of PubMed (https://www.ncbi.nlm.nih.gov/ pubmed/), MEDLINE (https://www.ncbi.nlm.nih.gov), and Scopus (https://www.scopus.com) databases from January 1997 to May 2017. Articles in languages other than English and those published before 1997 were excluded. The search strategy consisted of the following keywords specific to each database: B-Lynch, uterine compression suture, and uterine preserved surgery. In addition, articles related to B-Lynch sutures were included.

\section{Statistical analysis}

JMP Pro version 13.1 software (SAS Institute, Tokyo, Japan) was used to perform statistical analyses. Categorical variables were compared using the Fisher's exact tests, while continuous variables were compared using the one-way analysis of variance. A probability $(p)$ value of $<0.05$ was considered statistically significant.

\section{Ethical approval}

The study protocol was approved on July 19, 2017, by the Ethics Committee of Osaka University (approval no. 17129).

Table 1 Demographic characteristics of women with uterine compression sutures

\begin{tabular}{|c|c|c|c|c|c|c|c|c|c|}
\hline & \multicolumn{2}{|l|}{ Total $(n=47)$} & \multicolumn{2}{|l|}{ Group A $(n=7)$} & \multicolumn{2}{|l|}{ Group B $(n=21)$} & \multicolumn{2}{|l|}{ Group C $(n=19)$} & \multirow[b]{2}{*}{$p$ value } \\
\hline & $n$ & $\%$ & $n$ & $\%$ & $n$ & $\%$ & $n$ & $\%$ & \\
\hline Age (years) & $37.5 \pm 4.5(25-49)$ & & $39.6 \pm 5.4(34-49)$ & & $37.4 \pm 4.3(25-45)$ & & $36.5 \pm 4.3(27-46)$ & & 0.652 \\
\hline$<35$ & 7 & 17.1 & 6 & 85.7 & 18 & 85.7 & 15 & 78.9 & 0.870 \\
\hline$\geq 35$ & 34 & 82.9 & 1 & 14.3 & 3 & 14.3 & 4 & 21.1 & \\
\hline \multicolumn{10}{|l|}{ Parity } \\
\hline Primipara & 37 & 78.7 & 5 & 71.4 & 14 & 66.7 & 18 & 94.7 & 0.07 \\
\hline Multipara & 10 & 22.3 & 2 & 28.6 & 7 & 33.3 & 1 & 5.3 & \\
\hline BMI & $23.7 \pm 3.0(18.1-30.9)$ & & $23.9 \pm 3.8(19.3-28.3)$ & & $23.5 \pm 2.7(18.9-29.2)$ & & $23.8 \pm 3.1(18.1-30.9)$ & & 0.541 \\
\hline $\begin{array}{l}\text { Gestational weeks at } \\
\text { delivery }\end{array}$ & $37.8 \pm 2.0(33-41)$ & & $37.8 \pm 1.6(36-41)$ & & $37.6 \pm 2.2(33-41)$ & & $38.0 \pm 1.6(35-41)$ & & 0.652 \\
\hline Preterm delivery & 9 & 19.1 & 0 & 0 & 5 & 23.8 & 4 & 21.1 & 0.531 \\
\hline Birthweight (g) & $\begin{array}{l}2945.8 \pm 581.5 \\
(1616-4556)\end{array}$ & & $\begin{array}{l}2912.3 \pm 240.4 \\
(2548-3278)\end{array}$ & & $\begin{array}{l}2929.9 \pm 693.9 \\
(1616-4244)\end{array}$ & & $\begin{array}{l}2971.8 \pm 548.2 \\
(2304-4556)\end{array}$ & & 0.976 \\
\hline \multicolumn{10}{|c|}{ Indication of cesarean delivery } \\
\hline Placenta previa & 4 & 8.5 & 2 & 28.6 & 1 & 4.8 & 1 & 5.3 & 0.193 \\
\hline $\begin{array}{l}\text { Previous cesarean } \\
\text { delivery }\end{array}$ & 9 & 19.1 & 1 & 14.3 & 7 & 33.3 & 1 & 5.3 & 0.078 \\
\hline Breech presentation & 2 & 4.3 & 1 & 14.3 & 0 & & 1 & 5.3 & 0.142 \\
\hline Arrest of labor & 14 & 31.9 & 1 & 14.3 & 6 & 28.6 & 7 & 36.8 & 0.578 \\
\hline $\begin{array}{l}\text { Non-reassuring fetal } \\
\text { status }\end{array}$ & 4 & 8.5 & 1 & 14.3 & 2 & 9.5 & 1 & 5.3 & 0.799 \\
\hline Twins & 6 & 12.8 & 0 & 0.0 & 2 & 9.5 & 4 & 21.0 & 0.503 \\
\hline Others & 7 & 14.5 & 1 & 14.3 & 2 & 9.5 & 4 & 21.0 & \\
\hline \multicolumn{10}{|l|}{ Type of cesarean delivery } \\
\hline Elective & 16 & 34.0 & 2 & 28.5 & 7 & 33.3 & 7 & 36.8 & 0.92 \\
\hline Emergent & 31 & 66.0 & 5 & 71.5 & 14 & 66.7 & 12 & 63.2 & \\
\hline \multicolumn{10}{|l|}{ Suture type } \\
\hline B-Lynch & 28 & 57.1 & 7 & 100 & 21 & 100 & 0 & 0 & \\
\hline Modified Hayman & 21 & 42.9 & 0 & 0 & 0 & 0 & 21 & 100 & \\
\hline
\end{tabular}

Data are presented as $n(\%)$ or mean \pm standard deviation, unless otherwise specified 


\section{Results}

\section{Surgical outcomes of UCSs with the use of different} sutures

Of the 2123 cesarean deliveries during the study period, 162 had estimated blood loss of $>1500 \mathrm{~mL}$ due to the atonic bleeding. The B-lynch or modified Hayman suture technique was performed in 47 patients included in this analysis (7 in group A, 21 in group $\mathrm{B}$, and 19 in group $\mathrm{C}$ ). The patients' baseline characteristics and surgical outcomes are shown in Tables 1 and 2, respectively. There were no significant differences in patient characteristics among the three groups (Table 1). No patient developed severe complications, such as uterine necrosis and pyometra. There were no significant differences in the endometritis rates among the three groups. The uterine preservation rate was significantly lower in group A than in groups B and C (43.9\% vs. 95.2 and $89.5 \%$, respectively; $p=0.006$; Table 2 ). There were no significant differences in the uterine preservation rates between groups $\mathrm{B}$ and $\mathrm{C}(p=0.56)$. No severe complications were detected in the follow up examination, and no patients visited our hospital with abnormal symptoms after the follow up examination.

\section{Needles and sutures used for UCS in previous studies}

Studies identified with Pubmed, MEDLINE, and Scopus were 243, 258, and 305, respectively. Seventy six studies mentioned the type of sutures in their studies, and approximately $80 \%$ of studies used Polyglactin 910 and Catgut sutures (data not shown). No dedicated suture for UCSs was identified.
Literature review showed that the three dedicated needles including our study were used for UCSs: No. 1 poliglecaprone 25 suture (W3709; Ethicon Endo-Surgery, Inc.), which was developed to perform the B-Lynch technique [16, 17], and a $100 \mathrm{~mm}$ custom made needle (AZNJ100N, Akiyama, Tokyo, Japan), as reported by Yano et al., which was developed to perform the MY suture technique [18]. We have summarized the surgical outcome of the dedicated needles and sutures for UCSs (Table 3) $[5,19,20]$. Literature review also showed that 2-Monodiox ${ }^{\circledast}$ is the first dedicated specific blunt straight needle for UCSs. This study is the first to report on the use of this needle and suture type. 2-Monodiox ${ }^{\oplus}$ could perform modified Hayman suture, and a supplementary video file shows this in more detail (Additional file 1).

\section{Discussion}

We developed a dedicated suture and needle for UCS and successfully showed the similar uterine preservation rate with the B-Lynch technique with No. 1 sutures in this study. Literature review showed that this analysis is the first to compare the three types of needles and sutures used for UCSs, and the review results could make interesting discussion on the current state of sutures and needles used for UCSs.

A comparison of the efficacy of different needles and sutures used as UCSs in our institution revealed that the B-Lynch technique with No. 1 sutures achieved better outcomes than those with No. 0 sutures. Thus, the B-Lynch technique should not be performed with No. 0 sutures, because the uterine preservation rate was significantly lower. Furthermore, our literature review showed that no previous study with a large number of

Table 2 Postoperative outcomes of women with uterine compression sutures

\begin{tabular}{|c|c|c|c|c|c|c|c|c|c|}
\hline & \multicolumn{2}{|c|}{ All cases $(n=41)$} & \multicolumn{2}{|c|}{ Group A $(n=7)$} & \multicolumn{2}{|c|}{ Group B $(n=21)$} & \multicolumn{2}{|c|}{ Group C $(n=19)$} & \multirow[b]{2}{*}{$p$ value } \\
\hline & $n$ & $\%$ & $n$ & $\%$ & $n$ & $\%$ & $n$ & $\%$ & \\
\hline Estimated blood loss (ml) & $\begin{array}{l}2358 \pm 960 \\
(1500-6600)\end{array}$ & & $\begin{array}{l}3682 \pm 1481 \\
(2200-6600)\end{array}$ & & $\begin{array}{l}2110 \pm 659 \\
(1500-4000)\end{array}$ & & $\begin{array}{l}2143 \pm 960 \\
(1500-3600)\end{array}$ & & \\
\hline Transfusion & 22 & 53.6 & 7 & 100 & 10 & 47.6 & 8 & 42.1 & 0.02 \\
\hline Duration of surgery (min) & $111.6 \pm 44.1$ & & $156.9 \pm 41.8$ & & $108.2 \pm 42.3$ & & $98.6 \pm 37.4$ & & 0.128 \\
\hline \multicolumn{10}{|l|}{ Additional treatment } \\
\hline Balloon tamponade & 3 & 7.3 & 0 & 0 & 1 & 4.8 & 3 & 15.8 & 0.359 \\
\hline UAE & 0 & 0 & 0 & 0 & 0 & 0 & 0 & 0 & 1.00 \\
\hline Balloon tamponade $\rightarrow$ UAE & 1 & 2.4 & 0 & 0 & 0 & 0 & 1 & 5.3 & 0.553 \\
\hline Hysterectomy & 6 & 14.6 & 4 & 57.1 & 1 & 4.8 & 2 & 10.5 & 0.006 \\
\hline \multicolumn{10}{|l|}{ Postoperative complications } \\
\hline Endometritis & 5 & 12.2 & 0 & 0 & 3 & 14.3 & 2 & 10.5 & 0.836 \\
\hline lleus & 6 & 14.6 & 0 & 0 & 2 & 9.5 & 4 & 21.1 & 0.503 \\
\hline
\end{tabular}

Data are presented as $n$ (\%) or mean \pm standard deviation, unless otherwise specified Bold indicates statistical significance

UAE Uterine artery embolization 


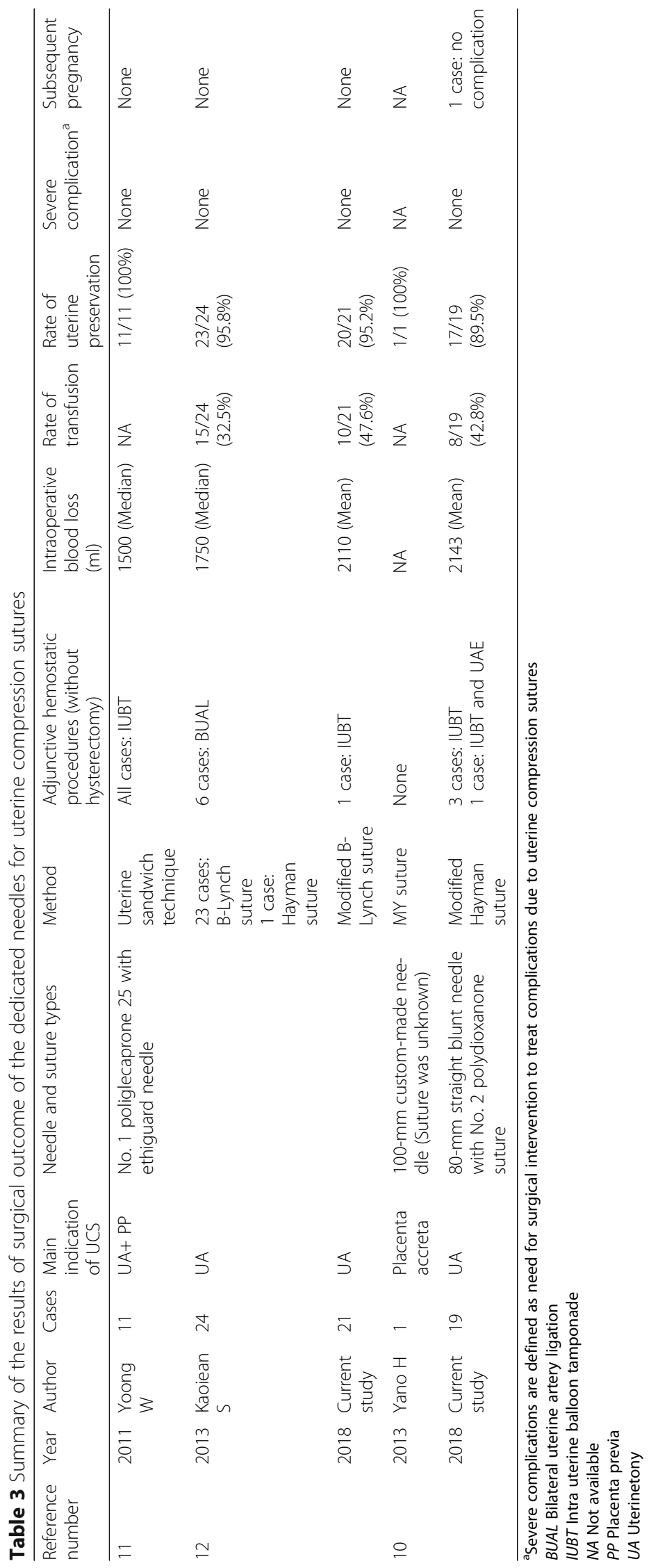


patients has investigated the B-Lynch technique with No. 0 sutures. Our results also suggested that the kind of needles and sutures might have affected the surgical outcome of UCSs. Although groups B and C showed similar uterine preserve rates, discussion about the needles and sutures was difficult because the comparison was not only between different needles and sutures but between different surgical techniques as well. Further studies, such as comparing the same UCS technique with different sutures and needles, are needed to compare the different type of sutures and needles.

Uterine atony is one of the most common causes of $\mathrm{PPH}$, and a simple and effective procedure is ideal in such an emergent situation [21]. A dedicated needle and heavy suture for UCSs are essential for efficient and effective suture placement. We speculated that a dedicated needle could help clinicians to rapidly perform the Hayman, Cho, and MY suture techniques. Therefore, Osaka university and Alfresa Pharma Corporation developed a specific blunt straight needle with No. 2 polydioxanone sutures. We tried to create extremely blunt needle that can avoid the tearing of the surgeon's glove, bladder, bowel, and rectum, but can easily penetrate the uterine wall in the anterior to posterior direction. No dedicated straight blunt needle has been available for UCSs, and straightening of a curved needle to place UCSs or using liver needle for UCSs have been reported [22-24]. We considered that straightening a curved needle or using liver needle is not ideal and not safe to perform UCSs. Therefore, we developed a dedicated straight blunt needle to improve the current state of straight needles available for UCSs. We considered that using a straight needle was not necessary for UCSs when performing the B-Lynch technique; however, the Hayman, Cho, and MY techniques have been performed using a straight or liver needle in previous studies, and these procedures may be more accessible once a straight blunt needle is developed [25-27]. Future studies are needed to show the simplicity of this device for use in UCSs. In addition, we expected that the dedicated straight blunt needle for UCS would be useful for placenta previa because performing UCSs toward the lower uterine segment is very difficult compared with the uterine body [28]. Further studies are now ongoing at our institution to show the efficacy and simplicity of 2 -Monodiox ${ }^{\oplus}$ for placenta previa.

Although, it is only our opinion, we felt that the modified Hayman suture technique with 2-Monodiox ${ }^{\circ}$ could be rapidly performed. Unfortunately, it was not possible to show the benefits of modified Hayman suture technique with 2 -Monodiox ${ }^{\circ}$ because various factors about performing UCSs were not investigated (e.g., time required to perform UCSs, the amount of bleeding after UCSs, surgeons' opinion) and neither compared these results with other sutures and needles; thus, this was the limitation of our study. Instead, we considered that our video file could show the simplicity of 2 -Monodiox ${ }^{\circ}$ (Additional file 1). Our literature review showed that only three dedicated needles were used for UCSs: No. 1 poliglecaprone 25 suture (W3709; Ethicon Endo-Surgery, Inc.), which was developed to perform the B-Lynch technique [16, 17], and a customized sizable curved needle, as reported by Yano et al., which was developed to perform the MY suture technique. ${ }^{18}$ W3709 was recommended by B-Lynch et al. as the most suitable material for the B-Lynch suture. However, our literature review revealed that about $80 \%$ of the included studies used Polyglactin 910 and Catgut sutures (data not shown), and W3709 was used in three reports (including our study). Zhang $\mathrm{Z}$ et al. considered that this is because W3709 was not available in most hospitals [29].

Our study has two strong biases. Firstly, it is the selection bias of our study. Our study focused on the efficacy of different needles and sutures for UCSs to the uterine body due to atonic bleeding; therefore, most of the high risk and severe $\mathrm{PPH}$ patients such as placenta previa and placenta previa complicated with placenta accreta cases, have not been included. These selection biases resulted in low incidence of severe PPH. Secondly, it is the lack of multivariate analysis to analyze variable factors whether these factors affect uterine preservation rate (B-lynch, Hayman, needle, parity, the number of previous cesarean delivery, etc.). Also, small sample sizes were included in this study that did not allow us to perform a multivariate analysis, which is the strong bias of this study.

The strength of this study was that it is the first study comparing needles and sutures for UCSs and the first report of UCSs using a dedicated blunt straight needle. The limitation to this study is the lack of data regarding the benefits of a dedicated blunt straight needle and suture for UCSs, and it was not possible to investigate the differences in the efficacy of each needle and suture to assess the uterine preservation rate among the different UCS types.

\section{Conclusion}

The present retrospective study focused on sutures and needles used for UCSs. Three types of sutures were compared and our data showed that No. 0 sutures should not be used for B-Lynch suture. Our dedicated blunt straight needle with No. 2 polydioxanone sutures (2-Monodiox ${ }^{\circ}$ ) could perform modified Hayman suture with similar uterine preservation rates when performed with B-Lynch technique with No. 1 sutures. Our future studies are expected to show the efficacy and simplicity of 2-Monodiox ${ }^{\circ}$. 


\section{Additional file}

Additional file 1: Our method of Modified Hayman suture with 2 Monodiox ${ }^{\circledR}$ sutures. This patient experienced $3050 \mathrm{ml}$ of intraoperative bleeding due to the uterine atony. The surgeon could penetrate uterine wall anterior to posterior easily. Owing to the blunt straight needle and heavy suture, it was easy to perform modified Hayman suture effectively. In this video file, UCS could control the postpartum hemorrhage. (WMV $67341 \mathrm{~kb})$

\section{Abbreviations}

PPH: Postpartum hemorrhage; UCS: Uterine compression suture

\section{Acknowledgements}

The authors thank H. Abe and K. Sakiyama for administrative assistance in the preparation of this manuscript. Alfresa Pharma Corporation contributed to developed a dedicated blunt straight needle with No. 2 polydioxanone sutures.

\section{Funding}

This work was supported by a Grant-in-Aid for Scientific Research from the Ministry of Education, Science, Sports and Culture of Japan (17 K11278 to SM).

\section{Availability of data and materials}

The dataset used and/or analysed during the current study are available from the corresponding author on reasonable request.

\section{Authors' contributions}

ShM, ME, SN, SaM, TM, KM, AK, and TTa made substantial contributions to conception and design, collected the clinical data. TTo, TTa, YU, and TK contributed to the data analysis and helped in drafting the manuscript. TK conceived and supervised this study and gave final approval of the version to be published. All authors read and approved the final manuscript.

\section{Ethics approval and consent to participate}

This study was approved by the Institutional Review Board and the Ethics Committee of the Osaka University Hospital (approval \#16077, approved on June 10, 2016)

\section{Consent for publication}

Not applicable.

\section{Competing interests}

The authors report no conflicts of interest concerning the materials or methods used in this review or the findings specified in this paper. The authors have no competing financial interests related to this study.

\section{Publisher's Note}

Springer Nature remains neutral with regard to jurisdictional claims in published maps and institutional affiliations

\section{Author details}

'Department of Obstetrics and Gynecology, Osaka University Graduate School of Medicine, 2-2 Yamadaoka, Suita, Osaka 565-0871, Japan. 2Department of Obstetrics and Gynecology, Otemae Hospital, 1-5-34, Otemae, Tyuuouku, Osaka 540-0008, Japan.

Received: 20 November 2018 Accepted: 1 March 2019

Published online: 11 March 2019

\section{References}

1. Maswime S, Buchmann E. A systematic review of maternal near miss and mortality due to postpartum hemorrhage. Int J Gynaecol Obstet. 2017;137:1-7

2. Committee on Practice B-O. Practice bulletin no. 183: postpartum hemorrhage. Obstet Gynecol. 2017;130:e168-e86.
3. Suzuki Y, Matsuzaki S, Mimura K, Kumasawa K, Tomimatsu T, Endo M, et al. Investigation of perioperative complications associated with use of uterine compression sutures. Int J Gynaecol Obstet. 2017;139:28-33.

4. B-Lync C, Coker A, Lawal AH, Abu J, Cowen MJ. The B-Lynch surgical technique for the control of massive postpartum haemorrhage: an alternative to hysterectomy? Five cases reported. Br J Obstet Gynaecol. 1997;104:372-5.

5. Matsubara S, Yano H, Ohkuchi A, Kuwata T, Usui R, Suzuki M. Uterine compression sutures for postpartum hemorrhage: an overview. Acta Obstet Gynecol Scand. 2013;92:378-85.

6. Nishikawa A, Matsuzaki S, Mimura K, Kanagawa T, Kimura T. Short interpregnancy interval after B-Lynch uterine compression suture: a case report. Clin Exp Obstet Gynecol. 2016;43:434-6.

7. Hayman RG, Arulkumaran S, Steer PJ. Uterine compression sutures: surgical management of postpartum hemorrhage. Obstet Gynecol. 2002;99(3):502-6.

8. Matsuzaki S, Tanaka M, Kimura T. Response to 'Letter to "Cervical varix complicated by placenta previa: A case report and literature review": A novel simple abdominal traction stitch (Matsubara) to hold the Bakri balloon'. J Obstet Gynaecol Res. 2016;42:1627-628.

9. Takahashi $H$, Baba $Y$, Usui $R$, Suzuki $H$, Horie $K$, Yano $H$, et al. Matsubara-Yano suture: a simple uterine compression suture for postpartum hemorrhage during cesarean section. Arch Gynecol Obstet. 2019;299:113-21.

10. El-Sokkary M, Wahba K, El-Shahawy Y. Uterine salvage management for atonic postpartum hemorrhage using "modified lynch suture". BMC Pregnancy Childbirth. 2016;16:251. https://doi.org/10.1186/s12884-016-1000-2.

11. Acar A, Karatayli R, Sayal B, Elçi A. A new surgical approach for the management of severe postpartum hemorrhage due to uterine atony: preliminary results in 27 cases. Clin Exp Obstet Gynecol. 2015;42:202-7.

12. Zhao Y, Zhang Y, Li Z. Appropriate second-line therapies for management of severe postpartum hemorrhage. Int J Gynaecol Obstet. 2014;127:180-2.

13. El Refaeey AEA, Abdelfattah H, Mosbah A, Gamal AM, Fayla E, Refaie W, et al. Is early intervention using Mansoura-W uterine compression sutures an effective procedure in the management of primary atonic postpartum hemorrhage?: A prospective study. BMC Pregnancy Childbirth. 2017;17:160. https://doi.org/10.1186/s12884-017-1349-x.

14. Matsubara S, Kuwata T, Baba Y, Usui R, Suzuki H, Takahashi H, et al. A novel 'uterine sandwich' for haemorrhage at caesarean section for placenta praevia. Aust N Z J Obstet Gynaecol. 2014;54:283-6.

15. Ali MK, Badee AY, Abbas AM, Shazly SA. A novel technique for modified BLynch suture for the control of atonic postpartum haemorrhage. Aust N Z J Obstet Gynaecol. 2013;53:94-7.

16. Price $\mathrm{N}$, Lynch C. Uterine necrosis following B-Lynch suture for primary postpartum haemorrhage. BJOG. 2006;113:1341.

17. Price N, BL C. Technical description of the B-Lynch brace suture for treatment of massive postpartum hemorrhage and review of published cases. Int J Fertil Womens Med. 2005;50:148-63.

18. Yano H, Kuwata T, Kosuge $\mathrm{S}$, Matsubara S. A long curved needle with a large radius for uterine compression suture. Acta Obstet Gynecol Scand. 2013;92:988-9.

19. Yoong W, Ridout A, Memtsa M, Stavroulis A, Aref-Adib M, Ramsay-Marcelle $Z$, et al. Application of uterine compression suture in association with intrauterine balloon tamponade ('uterine sandwich') for postpartum hemorrhage. Acta Obstet Gynecol Scand. 2012;91:147-51.

20. Kaoiean S. Successful use of the B-Lynch uterine compression suture in treating intractable postpartum hemorrhage after cesarean delivery in Rajavithi hospital. J Med Assoc Thail. 2013;96:1408-15.

21. Weisbrod AB, Sheppard FR, Chernofsky MR, Blankenship CL, Gage F, Wind G, et al. Emergent management of postpartum hemorrhage for the general and acute care surgeon. World J Emerg Surg. 2009;4:43.

22. El-Refaeey AA, Gibreel A, Fawzy M. Novel modification of B-Lynch uterine compression sutures for management of atonic postpartum hemorrhage: W uterine compression sutures. J Obstet Gynaecol Res. 2014;40:387-91.

23. Li GT, Li XF, Liu YJ, Li W, Xu HM. Symbol " \&" suture to control atonic postpartum hemorrhage with placenta previa accreta. Arch Gynecol Obstet. 2015;291:305-10.

24. Li GT, Li XF, Li J, Liu YJ, Xu HM. Reflexed compression suture for the Management of Atonic Postpartum Hemorrhage with an abnormally adherent placenta. Gynecol Obstet Investig. 2015;80:228-33.

25. Nanda S, Singhal SR. Hayman uterine compression stitch for arresting atonic postpartum hemorrhage: 5 years experience. Taiwan J Obstet Gynecol. 2011;50:179-81 
26. Li GT, Li XF, Li G. Simpler compression suture for controlling atonic postpartum hemorrhage. J Obstet Gynaecol Res. 2015;41:993-4.

27. Cho JH, Jun HS, Lee CN. Hemostatic suturing technique for uterine bleeding during cesarean delivery. Obstet Gynecol. 2000;96:129-31.

28. Li GT, Li XF, Wu B, Li G. Longitudinal parallel compression suture to control postopartum hemorrhage due to placenta previa and accrete. Taiwan J Obstet Gynecol. 2016;55:193-7.

29. Zhang ZW, Liu CY, Yu N, Guo W. Removable uterine compression sutures for postpartum haemorrhage. BJOG. 2015;122:429-33.

Ready to submit your research? Choose BMC and benefit from:

- fast, convenient online submission

- thorough peer review by experienced researchers in your field

- rapid publication on acceptance

- support for research data, including large and complex data types

- gold Open Access which fosters wider collaboration and increased citations

- maximum visibility for your research: over $100 \mathrm{M}$ website views per year

At $B M C$, research is always in progress.

Learn more biomedcentral.com/submissions 